\title{
Correction to: The Economics of Target Balances
}

\section{Correction to:}

H.-W. Sinn, The Economics of Target Balances, https://doi.org/10.1007/978-3-030-50170-9

The original version of the chapters 5 and 12 was revised. In Chapter 12, on Page 103 of the book, the official German government data was corrected. In Chapter 5, On p. 36. the term "foreign exchange, equity" was replaced with "revaluation adjustments". The term STEPS market was changed to STEP market twice in the book, on p. 34 of Chapter 5, and on p. 145, right column. The chapter and book have been updated with the change.

The updated versions of the chapters can be found at https://doi.org/10.1007/978-3-030-50170-9_5 https://doi.org/10.1007/978-3-030-50170-9_12 